\title{
WHAT IS THE MOST EFFECTIVE WAY OF ARRANGING THE LENGTH AND USE OF THE CLASS PERIOD?
}

Chairman: C. E. Williams, Principal, High School, Raton, New Mexico.

Discussants:

Robert V. Cogger, Principal, Memorial High School, Elmont, New York. Morrell L. Vehslage, Principal, High School, Dover, Delaware.

\section{Summary of the presentation made by BERTRAM H. HOLLAND}

TH

HE key to effective use of class periods is adequate planning by classroom teachers and administrators. Short class periods require more careful planning. Moreover, if class periods are fully planned, there is less need for longer periods. There is no magic in a long period as compared to a short period. In fact, there is danger that long class periods will encourage time wasting because it is possible to accomplish much in long periods even without careful planning. This is more likely to be the case when a school changes from short to long periods. Teachers tend to use the longer period to do more of the same thing, such as lecture-discussion especially in academic subjects. In laboratory subjects, there is a similar danger, only this time it is more likely to be pupils who will dawdle in getting out and returning equipment, in changing clothes, and in cleaning up the laboratory at the end of the period.

To be sure, there is a minimum length of time below which it is impossible to complete a laboratory exercise. This is true whether it is art, physical education, chemistry, or woodworking no matter how well planned the lesson or how much students exert themselves. Certainly if a class period is so short that as much or more time is needed to get out equipment, return it, and restore the space to proper condition for the next class than is left for actual laboratory experience, then the period is too short. In this case, double periods may be preferable to establishing uniformly longer periods for all subjects which do not need preparationrestoration time within the class period. Class periods ought to be long enough to allow at least twice as much time for laboratory work as for combined preparation-restoration. Also to be considered is the tension under which students and teachers must operate if they are to repeat this pressurized experience period after period during the day.

Once the decision has been made regarding the length and number of class periods in a school day, the next step is to plan for the most efficient use of the time within each class period. Planning for use of class time

Bertram H. Holland is Headmaster of Brookline High School, Brookline, Massachusetts. 
should be aimed at developing power on the part of students to do for themselves. If a school day is long enough for even the slowest students to complete all their school work in school time, then the fast workers have time on their hands. Not all worth-while educational activities can be accomplished within classrooms; e.g., library reference work. Time should be taken in class to teach students how to attack a problem, but somewhere along the line the student should be placed on his own responsibility to complete the problem by himself. No classroom is sufficiently self-contained to allow the ablest and most ambitious students to extend themselves fully within the confines of that room in a given subject no matter how long the period may be.

By the time students are graduated from high school, they ought to be able to manage their time for themselves to a large degree. This means that students must be given experience in budgeting time for study, in using resource materials, in verifying their own results, in correcting their own mistakes, and in becoming self-starting and self-directing. Supervised study under the aegis of the classroom teacher has merit, but it should not be carried on in the same manner year after year so that it becomes a crutch on which students lean. Certainly supervised study ought not to be conducted in the same way for twelfth-grade pupils as it is for ninthgrade pupils.

The unitary treatment of a subject lends itself best to teaching for power. A properly prepared unit assignment enables the teacher to provide for individual differences in terms of the developed abilities of his students and their goals. The objectives of every course should be stated in terms of minimum essentials to be required of everyone and desirable enrichment goals to be attained by some. Once these objectives have been formulated, the unit assignment may be prepared in terms of learning activities to be required of everyone and optional related activities to be done by those interested and able to dip deeper and wider for enrichment.

Whenever possible, both required and optional activities should be planned to be done outside of the classroom under the student's own management. Such homework assignments should be simple at first, but more demanding of initiative, creativity, and self-control as students mature month by month and grade by grade.

It is vital to have such unit assignments prepared in advance and duplicated so that each student receives a copy of required activities and such optional activities as appeal to him. Here is the point where adequate space for filing unit assignments and tests should be available to every teacher. Likewise, sufficient clerical personnel should be provided so that teachers need not duplicate their own unit assignments or tests but may spend their time and energy in improving units and unit assignments. The more that teachers can be relieved of repetitive clerical duties, the more they are able to devote themselves to educational activities requiring professional initiative and creativity. 
If a faculty cannot develop units and unit assignments all at once in all courses for an entire year (and few schools ever have done this even when teachers have been employed on a twelve-month basis to prepare these materials during summer vacation), then it is necessary to decide on a starting point. The writer has found that the most fruitful single activity to enable teachers to improve their use of class time has been to ask each teacher to submit study guides or assignment sheets and tests for duplication by the office staff during vacation days. This not only saved teachers the time needed to duplicate these assignment sheets themselves but also encouraged them to prepare such materials in advance which was a great help to students.

Most teachers have a good idea of what they are trying to accomplish. This is particularly true in school systems where courses of study have been developed and duplicated for use of teachers. It is not as common to find systematic development of duplicated assignment sheets or study guides for use of students on a school-wide basis. This latter I recommend as a reasonable "next step" in the implementation of courses of study. Certain specific advantages result from the use of duplicated assignment sheets are:

1. Serves as an introduction of the unit method to the school.

2. Saves time often lost in the usual ways of making assignments in classrooms.

3. Tells students what they will have to learn. references.

4. Makes possible more expanded reading through the use of outside

5. Takes the place of workbooks; is inexpensive.

6. Provides for a systematic form of assignments.

7. Expedites make-up of work lost by absence of pupils.

8. Is a guide for the substitute teacher during absence of regular teacher.

9. Is an incentive to study.

10. Serves as a review before tests and examinations.

11. Provides necessary information to students transferring to school systems during the year.

12. Minimizes the marking-up of textbooks.

13. Helps a teacher to adapt for better use a textbook which otherwise would be too difficult for the students.

14. Enables interested parents to see what students are required to do for homework.

15. Enables students to budget their time for study.

16. Enables a teacher to help indirectly at one time as many students as there are in the class. 


\section{Summary of the presentation made by LESTER W. ANDERSON}

NE of the most effective ways of using the class periods appears to be a plan wiich provides a generous amount of supervised study within the regular class pericd. Use of the class period in this way makes it possible for the pupil to receive assistance in his preparation from the teacher for whom the work is being prepared. Such provision makes it possible also to eliminate the large, unproductive study halls which have been so prevalent in our American high schools. Teachers can then concentrate on teaching rather than being study hall policemen.

In order to eliminate most study halls, schools have also had to require that all students elect six activities or subjects. However, this practice has provided additional enrichment of the pupil's program of studies. This statement is based on the assumption that it is desirable for students to study more than the usual four or five subjects so common in many high schools.

Recently, the writer completed an opinion survey of teachers who are teaching under the plan of five periods, seventy minutes in length. These teachers were enthusiastic in their support of the longer period. They were especially pleased with the additional time for supervised study. Testimony of these teachers emphasized the increased opportunity to help individual students.

Teachers of laboratory and activity type classes appear to be especially appreciative of the seventy-minute period. Subjects that require time to assemble equipment, to change clothing, or to clean up after the class activity are benefited by having more adequate work time during the class period. Longer assignments, experiments, or projects can be completed within the single period. This seems to provide greater continuity in the learning process.

Social studies classes and other classes that utilize field trips also find the additional time useful. More trips to local points of interest can be made within the allotted time. This reduces considerably the old headache of having students reporting late to the classes which follow the field trip. It also encourages greater use of local resources because there is time to make the trip more comfortably.

Lengthening the class periods is not the entire solution to the problem. If no other provision were made, students would have only five periods in the usual six-hour school day. This would decrease by one the number of subjects or activities which could be elected. Such a restriction is undesirable for most students. It is necessary, therefore, to devise a schedule which permits both the longer period and the election of at least six subjects or activities by all pupils.

Lester W. Anderson is Associate Professor of Education, University of Michigan, Ann Arbor, Michigan. 
The following plan for five seventy-minute periods is being used in a number of Michigan high schools to achieve the above conditions. Most schools that have adopted this plan had been using six fifty-five minute periods. A schedule of this type is intended:

1. To provide a larger amount of time for supervised study under the direction of the teacher for whom the work is being prepared

2. To make possible the elimination of large study halls

3. To provide a longer period for laboratory classes and field trips

4. To provide a longer activity period once a week.

The mechanics of preparing such a schedule are relatively simple. It is still necessary to prepare the six-period schedule in the same manner as is usually done. Changing the six-period to the five-period schedule is achieved by printing a conversion chart with the regular schedule. Here is an example of such a conversion chart.

\begin{tabular}{|c|c|c|c|c|c|}
\hline Period & Mon. & Tues. & Wed. & Thurs. & Fri. \\
\hline A & 1 & 1 & 1 & 1 & 6 \\
\hline B & 2 & 2 & 2 & 6 & 2 \\
\hline C & 3 & 3 & activity period & 3 & 3 \\
\hline D & 4 & 6 & 4 & 4 & 4 \\
\hline E & 6 & 5 & 5 & 5 & 5 \\
\hline
\end{tabular}

Periods $\mathrm{A}$ to $\mathrm{E}$ are all 70 minutes in length. The numbers 1 to 6 represent the periods on the usual six-period schedule.

For a typical ninth-grade student, taking (1) English, (2) civics, (3) general science, (4) band, (5) physical education, and (6) algebra, the weekly program card made with the conversion chart would be as follows.

\begin{tabular}{|c|c|c|c|c|c|}
\hline Period & Mon. & Tues. & Wed. & Thurs. & Fri. \\
\hline $\mathbf{A}$ & English & English & English & English & Algebra \\
\hline B & Civics & Civics & Civics & Algebra & Civics \\
\hline C & $\begin{array}{l}\text { General } \\
\text { Science }\end{array}$ & $\begin{array}{l}\text { General } \\
\text { Science }\end{array}$ & $\begin{array}{l}\text { Home-room, Class } \\
\text { Meetings, etc. }\end{array}$ & $\begin{array}{l}\text { General } \\
\text { Science }\end{array}$ & $\begin{array}{l}\text { General } \\
\text { Science }\end{array}$ \\
\hline D & Band & Algebra & Band & Band & Band \\
\hline $\mathbf{E}$ & Algebra & $\begin{array}{l}\text { Physical } \\
\text { Education }\end{array}$ & $\begin{array}{l}\text { Physical } \\
\text { Education }\end{array}$ & $\begin{array}{l}\text { Physical } \\
\text { Education }\end{array}$ & $\begin{array}{l}\text { Physical } \\
\text { Education }\end{array}$ \\
\hline
\end{tabular}


It should be noted that all classes will meet only four times per week under this arrangement. The increased time during the four days makes it possible, however, to meet adequately the time requirements of the Carnegie Unit. Full credit can still be given for the subjects even though there is one less meeting per week.

The process by which a faculty reaches the decision to utilize periods of 70 minutes is important also. Schools that have adopted the longer period have usually done so after considerable discussion by the faculty. Teachers must be in agreement with the idea of providing increased study time as part of the regular class activities if the plan is to operate effectively. No doubt some in-service activity is necessary in order to assist teachers in developing techniques in teaching students how to study.

It should be emphasized that the plan presented in this article is merely one way by which administrators can schedule classes to make it possible for teachers to do a more effective job with their pupils. Faculties should be encouraged to experiment with other plans which might be as effective or more effective than this one. In any event, it is possible for schools to do away with the large, unproductive study hall which has been such a universal feature of our American high schools. It is hoped that this will help to improve the effectiveness of the learning activities of all highschool boys and girls.

\section{WHAT ADMINISTRATIVE TECHNIQUES CONTRIBUTE TO BETTER PRINCIPAL-FACULTY RELATIONSHIPS?}

Chatrman: J. C. Blair, Director, Division of Secondary Education, State Department of Education, Montgomery, Alabama.

\section{Discussants:}

Nelson F. Hurley, Principal, Parkville Senior High School, Baltimore, Maryland.

Ralph L. W. Schmidt, Associate Professor of Education, Louisiana State University, Baton Rouge, Louisiana.

\section{Summary of the presentation made by OTTO HUGHES}

\footnotetext{
T

HE practice of democratic procedures in school administration is most essential to a sound educational program. Providing maximum educational opportunities for all American Youth of high-school age necessitates a sharing of responsibilities for the program of education by the principal

Otto Hughes is Principal of University School, Indiana University, Bloomington, Indiana.
} 